Insight, part of a Special Feature on Exploring Opportunities for Advancing Collaborative Adaptive Management (CAM): Integrating Experience and Practice

\title{
Insight into Enabling Adaptive Management
}

\author{
$\underline{\text { Lorne A. Greig }}^{1}$, David R. Marmorek $^{l}, \underline{\text { Carol Murray }}^{l}$ and $\underline{\text { Donald C. E. Robinson }}^{l}$
}

\begin{abstract}
The U.S. National Commission on Science for Sustainable Forestry recognized a need for effective adaptive management to support management for biological diversity. However, difficulties in implementing adaptive management in the U.S. Northwest Forest Plan led the Commission to wonder if comparisons across multiple adaptive management trials in the forest sector could provide insight into the factors that serve to enable or inhibit adaptive management. This comparison and the resulting discussions among a group of seasoned practitioners, with adaptive management experience at a variety of scales and levels of complexity, led to insights into a hierarchy of ten factors that can serve to either enable or inhibit implementation. Doing high quality adaptive management is about doing good science to enable learning from management experience. Enabling adaptive management though is about working with people to understand their concerns, to develop a common understanding and an environment of trust that allows adaptive management to proceed. Careful attention to enabling factors is critical to fulfilling the promise of adaptive management.
\end{abstract}

Key Words: adaptive management; enabling factors; forest; inhibiting factors

\section{INTRODUCTION}

Although the concept of adaptive management (AM) holds great promise, the practice of AM has been fraught with challenge. Lee (1999) observed that "Adaptive management has been more influential, so far, as an idea than as a practical means of gaining insight into the behavior of ecosystems utilized and inhabited by humans." More recently, Walters (2007) observed that of more than 100 case studies of attempts to implement AM, most failed in that no experimental management program was implemented, whereas others suffered from serious problems with their monitoring programs.

Work commissioned by the U.S. National Commission on Science for Sustainable Forestry (NCSSF) noted that complex conservation theories regarding biological diversity are difficult-if not impossible-to test through traditional experimental research and concluded that AM may be the best way to calibrate theories over time (Mitchell et al. 2004). Despite significant effort to implement AM in the Pacific Northwest Forest Plan, Stankey et al. (2003) found that AM had not translated easily into practice. Successful implementation of AM remained elusive, there were significant barriers to AM, and legal, organizational, and ideological changes were needed before AM implementation could be successful.

The NCSSF wondered "Can comparisons across ownerships show what factors enable AM to work and what factors inhibit successful implementation?" To address this question, we conducted a literature review, a nonrandom survey of public and private AM projects in various forest sectors (Table 1), and a workshop to discuss the results with AM practitioners.
The results of the literature review and survey provided the background to initiate workshop discussions. In this paper, we focus primarily on the insights gained during those discussions.

\section{METHODS}

The results of the literature review were used to inform our development of a consistent structure for the survey of AM projects. Literature on efforts to implement AM in a range of domains (Environmental and Social Systems Analysts Ltd. (ESSA) 1982, Lee 1993, 1999, MacDonald et al. 1997, Taylor et al. 1997, Walters 1997, McDonald et al. 1999, Alverts et al. 2001, Salafsky et al. 2001, Murray and Marmorek 2003, Stankey et al. 2003, 2005) reveals a number of inhibiting and enabling factors that can be grouped into three categories: attitude/philosophy, process, and resources. We expanded these three categories into ten factors based on work by Alverts et al. (2001).

The survey employed questions based on likely inhibiting or enabling factors identified in the literature review, together with openended questions to elicit independent insight. As smaller or inprogress projects are usually not found in the literature, we identified projects through contacts within our network and that of the NCSSF. This method of identifying AM projects is potentially biased toward identifying projects that are more successful.

Candidate projects were screened to ensure that they made sincere attempts to do AM, and projects that did not meet this criterion were excluded from the analysis. The number of projects included in the survey was constrained by the time available for its completion. An initial target of 16 projects was set, but 21 projects were identified and 19 included in the 
Table 1. Projects included in the survey.

\begin{tabular}{|c|c|c|}
\hline 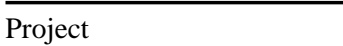 & Location & Summary $^{\dagger}$ \\
\hline $\begin{array}{l}\text { Tongass Wide Young } \\
\text { Growth Studies }\end{array}$ & Alaska & $\begin{array}{l}\text { 4-yr, } \$ 7 \mathrm{M} \text { federally led project to study the effect of stand thinning to encourage deer forage at } \\
\text { stem-exclusion stage; four trials, } 20 \text { replicates; strengthened by high level of trust among } \\
\text { members in different state agencies; high public visibility }\end{array}$ \\
\hline $\begin{array}{l}\text { Fort Valley Ecosystem } \\
\text { Restoration Project: }\end{array}$ & Arizona & $\begin{array}{l}\text { 7-yr, } \$ 1 \mathrm{M}, 3000 \text {-ha NGO-led study to restore forest health and fire-resistant stand structures at } \\
\text { the urban interface; seven thinning trials with replication; restoration goals achieved through } \\
\text { stakeholder workshops; decisions require unanimous agreement among } 24 \text { partner organizations; } \\
\text { challenge of finding commercial market for biomass }\end{array}$ \\
\hline McCully Creek Watershed & $\begin{array}{l}\text { British } \\
\text { Columbia }\end{array}$ & $\begin{array}{l}\text { 4-yr, } \$ 25,000,25,000 \text {-ha provincially led project to study stand and watershed response under } \\
\text { alternative thinning and small-area harvest entries; motivated by an economic and environmental } \\
\text { "crisis of change"; challenge of maintaining momentum during staff turnover and sequence of } \\
\text { single-year funding }\end{array}$ \\
\hline Forest Grassland Study & $\begin{array}{l}\text { British } \\
\text { Columbia }\end{array}$ & $\begin{array}{l}\text { Industry-led project to control forest encroachment of grasslands; planned as stand-scale multi- } \\
\text { year trials; challenge of not providing operational results in 1-2 years; perception of high cost and } \\
\text { company purchase in industry consolidation }\end{array}$ \\
\hline Adaptive Management of & British & 6-yr, $\$ 188,000,1000$-ha industry-led project thinning to discover silvicultural ways to enhance \\
\hline Pine-Lichen Woodlands & Columbia & $\begin{array}{l}\text { lichen for mountain caribou following harvest; nine trials, three replicates at stand scale; } \\
\text { motivated by desire to avoid land-use conflict; challenge of administrative centralization }\end{array}$ \\
\hline Coast Forest Strategy & $\begin{array}{l}\text { British } \\
\text { Columbia }\end{array}$ & $\begin{array}{l}\text { 6-yr, } \$ 3.8 \mathrm{M}, 800,000 \text {-ha industry-led variable retention harvesting and landscape zoning to } \\
\text { maintain biodiversity; nine trials at stand and watershed scale motivated by ecological and } \\
\text { aesthetic impact of clearcut; good cooperation among government, staff; including training and } \\
\text { information sharing between companies; independent peer-review panel; key outcome: do a few } \\
\text { things well, not many things poorly }\end{array}$ \\
\hline Donna Creek AM Trial & $\begin{array}{l}\text { British } \\
\text { Columbia }\end{array}$ & $\begin{array}{l}15 \text {-yr, } \$ 250,000,6000 \text {-ha province-industry partnership study to maintain snags and bird habitat; } \\
\text { three replicated stand-level trials; strengthened by consistent funding; would be improved by } \\
\text { additional replication, better spatial separation, and configuration of trials }\end{array}$ \\
\hline Ospika Mountain Goat AM & British & 7-yr, $\$ 1.1 \mathrm{M}$ province-industry partnership to determine whether goat migration is influenced by \\
\hline Trial & Columbia & $\begin{array}{l}\text { cut blocks at watershed scale; challenge of small goat population sample, interactions/negotiation } \\
\text { among forest licensees to design experimental cut blocks }\end{array}$ \\
\hline $\begin{array}{l}\text { Almanor Forest Group } \\
\text { Selection Harvesting }\end{array}$ & California & $\begin{array}{l}\text { 38,000-ha industry-led study of small openings to encourage natural regeneration of high-value } \\
\text { pine }\end{array}$ \\
\hline $\begin{array}{l}\text { Ponderosa Pine Forest } \\
\text { Partnership }\end{array}$ & Colorado & $\begin{array}{l}11-\mathrm{yr}, \$ 38,000,4000 \text {-ha federally led project to restore normal ecosystem; trials involve group } \\
\text { thinning and prescribed burn, motivated by need to restore ecosystem with natural range of } \\
\text { variation in stand structure; challenge of finding market for small-dimension wood, expertise in } \\
\text { prescribed burn; approaches shifted from academic-rigorous to pragmatic-less rigorous over } \\
\text { time. }\end{array}$ \\
\hline $\begin{array}{l}\text { Sustainable Mixed Wood } \\
\text { Practices in a Stand Level } \\
\text { AM Framework }\end{array}$ & Ontario & $\begin{array}{l}\text { 7-yr, } \$ 1 \mathrm{M} \text { provincially led partial harvesting to find sustainable operational practices for } \\
\text { mixedwood ecosystems; motivated by poor understanding of postharvest stand dynamics; } \\
\text { included AM training for all partners; challenge of time required to gain knowledge; staff } \\
\text { turnover }\end{array}$ \\
\hline Riparian Function Study & Oregon & $\begin{array}{l}\text { 3-yr, } \$ 115,000 \text { state-led study at plot-to- stand scale, } 24 \text { trials motivated by need to maintain } \\
\text { stream debris following harvest; good stakeholder support; design would be improved by BACI } \\
\text { (Before-After Control-Impact) and more replicates, improved attention to fish impacts at the } \\
\text { design step }\end{array}$ \\
\hline $\begin{array}{l}\text { Blue River Landscape } \\
\text { Study }\end{array}$ & Oregon & $\begin{array}{l}\text { 12-yr, } \$ 1.8 \mathrm{M}, 23,000 \text {-ha federally led as part of the Northwest Forest Plan, focus on emulation of } \\
\text { natural disturbance patterns and sustainable timber supply; strengthened by two key champions, } \\
\text { steady funding, history of science-management in area; challenged by time required to gain } \\
\text { knowledge, political climate, AM experiments curtailed by wildlife protection regulations }\end{array}$ \\
\hline Five Rivers Landscape & Oregon & 8 -yr, $\$ 1.5 \mathrm{M}, 13,000$-ha federally led stand- and landscape-level study as part of the Northwest \\
\hline Management Project & & $\begin{array}{l}\text { Forest Plan, goal to maintain late-successional stands with harvest supply through thinning; } \\
\text { strength was to make learning a NEPA goal; to link science to decisions; challenge of lack of } \\
\text { high-level commitment, fear of legal action, limited public capacity for involvement }\end{array}$ \\
\hline Applegate AM Area & Oregon & $\begin{array}{l}\text { 9-yr, } \$ 1 \mathrm{M}, 202,000 \text {-ha, federally led suite of many small projects; replicated trials to reduce bark } \\
\text { beetle risk, prescribed burning trials; involved collaborative public involvement; limited } \\
\text { integrated documentation }\end{array}$ \\
\hline
\end{tabular}




\begin{tabular}{|c|c|c|}
\hline $\begin{array}{l}\text { Commercial Thinning and } \\
\text { Swiss Needle Cast: }\end{array}$ & Oregon & $\begin{array}{l}8 \text {-yr, } \$ 1.6 \mathrm{M} \text { state-led trials with replicates to understand effects of fungal infection on Douglas- } \\
\text { fir, options for thinning that minimize outbreaks, response of host tree to disease }\end{array}$ \\
\hline $\begin{array}{l}\text { Culvert Replacement } \\
\text { Program }\end{array}$ & Oregon & $\begin{array}{l}\text { 4-yr, } \$ 350 \mathrm{~K} \text { industry-led project to improve fish passage through culverts; compared different } \\
\text { configurations and acceptance by spawners }\end{array}$ \\
\hline $\begin{array}{l}\text { Leave Tree Harvesting } \\
\text { System for Appalachian } \\
\text { Hardwoods }\end{array}$ & Virginia & $\begin{array}{l}5 \text {-yr, } \$ 50 \mathrm{~K}, 142,000 \text {-ha industry-led study to find partial-harvest alternatives to clearcut that } \\
\text { promote natural regeneration, improve wildlife habitat; strengthened by good leadership, } \\
\text { cooperation with researchers, small trials to demonstrate results; challenge of historical inertia } \\
\text { and clearcut tradition; markets for smaller trees }\end{array}$ \\
\hline Forests and Fish Report & Washington & $\begin{array}{l}\text { 8-yr, 3,200,000-ha, } \$ 24 \mathrm{M} \text { industry-led effort aimed at creating a management framework among } \\
\text { all state stakeholders, reducing uncertainty in stream habitats affected by forest practices; over } 50 \\
\text { research needs identified, using AM as key feature }\end{array}$ \\
\hline
\end{tabular}

Costs are 2006 U.S. dollars; more extensive summaries are found in Appendix 4 of Marmorek et al. (2006). analysis (Table 1). Once a project was selected for inclusion in the survey, we sought to identify a survey respondent within the organization who would be knowledgeable about the project's implementation, challenges, and outcomes. Interviews were held with several respondents to discuss and clarify survey results.

Given the small sample size and method for identifying AM projects, we do not consider the survey results to be representative of the full range of AM projects undertaken within the forest sector. Analysis of survey results was limited to an exploration of response patterns across organizational type and self-assessed grades of project success (A, B, C, or F). Although there is always a potential for bias in selfassessment, we found the respondents to be open about, and critical of, weaknesses in their own projects. Details of the survey results can be found in our report to the NCSSF (Marmorek et al. 2006).

All of the survey respondents were invited to attend the workshop. In addition to ourselves, 11 AM practitioners attended, of whom six had participated in the survey. The workshop began with a review of the results of the survey, and the discussion focused on developing insight into enabling AM, based on both the survey results and participants' personal experience.

\section{RESULTS}

Box 1: An adaptive approach is becoming essential to living in a very complex world.

AM should lead to better, more informed decisions by allowing managers to adjust programs in response to change, detect the effects of management actions, learn which practices best meet management objectives, improve understanding of system function, and share information/experiences.

Box 2: Federal and state laws regarding forest policy are based on a regulated forest to achieve a sustained yield; to minimize uncertainty and risk, for more stable expectations. This is the opposite of what most ecologists (and social scientists) now understand-it is dynamic and you can't stabilize it. Adaptive management is about, "how can you take this uncertainty and risk and move forward?"

All but one of the projects surveyed (Table 1) was considered by the project representative to be an AM success. The form of the projects, however, and the degree of success varied considerably. This variability provided valuable insights into how each factor affecting AM could change its influence (from enabling to inhibiting or vice versa) in different contexts, even within one project over time.

Our survey revealed that AM projects have led to the following advances: new forest practice rules for leave-trees on small and medium fish-bearing streams in Oregon; new methods for identifying perennial streams that require greater protection during forest operations in Washington; changes to some elements of standard practice for partial harvesting and regeneration, and proposed changes to ungulate winter range policy, in British Columbia (BC); modification to a BC forest company's variable retention group size to reduce costs and windthrow and to increase snags for cavity nesters; changes to forest practices to restore understory conditions favorable to deer in Alaska; and increased use of prescribed fire after mechanical treatment in Arizona.

\section{What Factors Enable AM?-Insights from Experience}

The results of the survey and workshop discussions led us to conclude that the ten factors should be considered in a hierarchy (Fig. 1). At the top of the hierarchy, the historical and current context motivates the need for AM. Leadership, executive direction, problem definition, and the structure of communications and the organization in the second tier, are all required to get AM initiatives successfully started. Once started, AM leaders can artfully focus on the third tier: community involvement, planning, funding, staff training, and the conduct of science.

Most of these factors can be either enabling or inhibiting. Leadership was the only factor that was not considered 
Fig. 1. Hierarchy of factors that enable adaptive management.

\section{Enabling Adaptive Management}

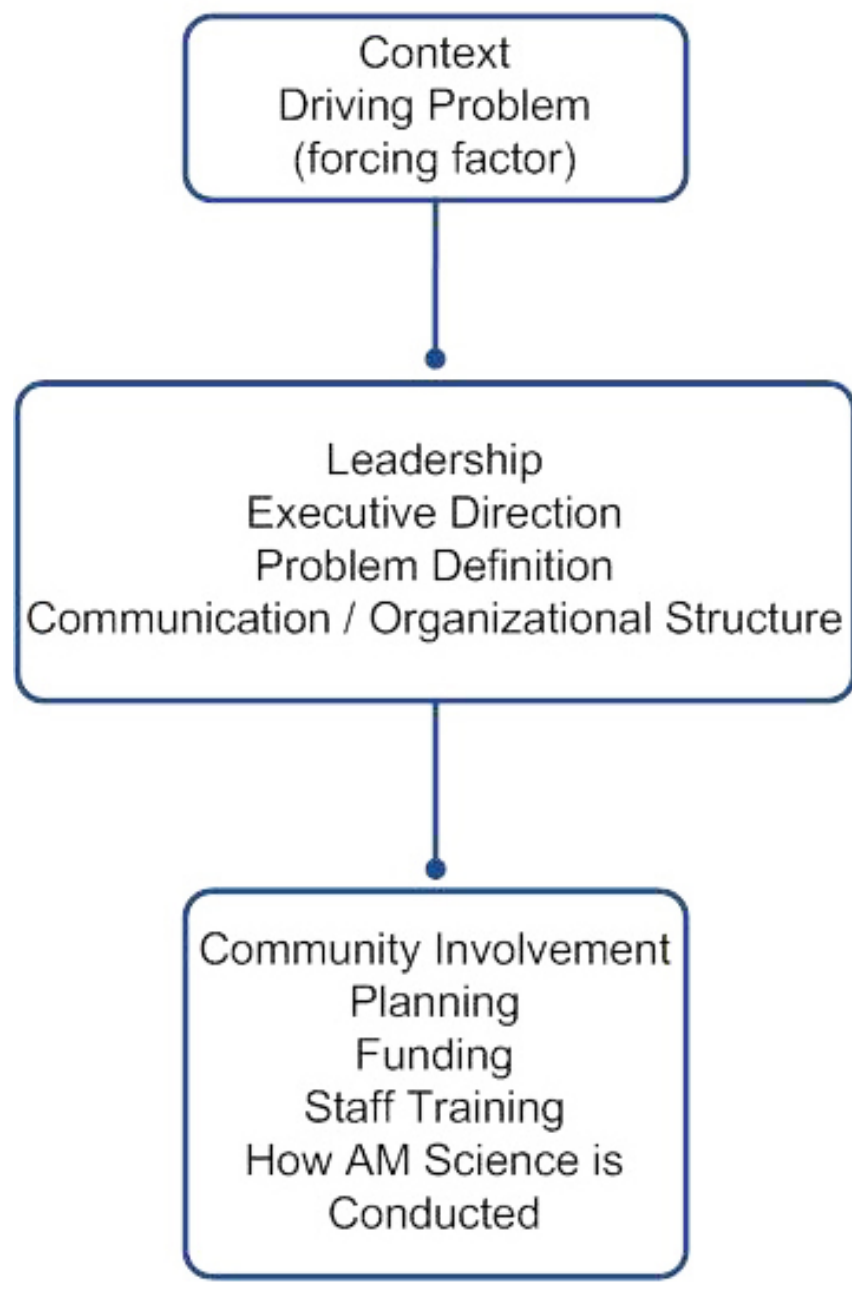

inhibiting by any of the survey respondents, even for those projects assigned a lower success rating. Executive direction and how science and AM is conducted were rated as enabling for more successful projects. This is likely because having an explicit AM mandate or a legal requirement for AM ensures project persistence through various challenges. The historical context was more often reported as inhibiting than other factors, perhaps because AM projects often grow from conflicts over management and values, where a lack of trust has developed.

No major differences were found between government-led and private-led projects, possibly due to our sample size. More private-led projects would be needed to conclude whether there are any real differences across sectors.

In addition to these ten factors, elements or issues arising at each of the six steps in the AM cycle (Fig.2) can also serve to either enable or inhibit AM; it depends on how these steps are done, and the institutional support for each one. The overall results suggest that all of these steps are important, and all were considered enabling (to varying degrees) by more than two-thirds of the survey respondents. The latter part of the cycle (closing the loop) was considered to be more enabling by private sector respondents than public sector respondents. Step 1, assessing the problem, was considered enabling by all of the respondents; it improves understanding and sets the direction for what you decide to do. Surprisingly, elements of or issues with all other steps were considered somewhat inhibiting by at least one respondent. For example, some respondents felt that the rigorous experimental design in Step 2 could be inhibiting if it reduced the momentum for implementing AM, or extended the experiment's duration beyond the time frames of decision makers. Other respondents stated that a strong, peer-reviewed experimental design was critical to generating clear outcomes and improving public acceptance of subsequent decisions.

Fig. 2. The adaptive management cycle.



\section{Historical and Current Context}

Box 3: First, you need some problem or some driving force to get an AM project started.

The current and historical context is what gives rise to the recognition that there is a problem to be addressed through an AM approach. Other important aspects of the context are the 
existing relationships between stakeholders, the degree of risk aversion reflected in regulations, and the corporate culture. It is very much about site specificity, taking into account social issues, and it is important to pay special attention to understanding the nature of the relationships in place. Doing so will require a dispassionately honest appraisal.

Box 4: There would not have been a Forest Plan if there was not a spotted owl.

The context in which the initiative arises can cause it to develop in very different ways. For example, in the development of the Northwest Forest Plan, development of the Applegate Adaptive Management Area was in some respects an artifact of the existing relationship among stakeholders. The AM approach was very much community-led, and the plan served essentially to federally codify what was already in place. Development of the AM initiative in the Central Cascades developed differently, taking advantage of the relationship between the research community and land managers. Although the specific nature of the relationships that served to enable development of these initiatives was different, in either case what was important were the relationships among key stakeholders.

\section{Leadership}

Leadership is essential but not sufficient for success: a common theme in the workshop discussions was that support is important from all levels of an organization. Regardless of the organizational level at which leadership for an AM initiative may be rooted, a key attribute of successful leadership is effective communication that gains broad support. In our survey, respondents consistently indicated that leadership strongly enabled AM, regardless of overall project success, reinforcing the conclusion that leadership is necessary but not sufficient for good outcomes.

In some cases, projects that were initiated with top-down leadership — but did not have support at lower levels — did not work well in the field, suggesting that leadership at local levels is important for success.

Box 5: Forest supervisors are important and extremely powerful; their involvement can make all the difference in the world.

This does not mean that top-down initiatives cannot be successful, but when AM projects are initiated from the top down, it is important to also secure support at lower levels in the organization. Securing long-term support requires legitimacy within an organization; it is important that people understand why the initiative is needed. It is also important to integrate the initiative in the organization's performance metrics. It is unfair to individuals to ask them to undertake a project when their performance is evaluated on other factors. Adaptive management must be part of what is measured for performance evaluation at the field level.

\section{Executive Direction (Corporate Culture)}

Executive engagement may occur as either executive direction or as executive support.

Box 6: Organizational buy-in indicates an agreement that is fundamental to getting the results incorporated into management programs.

Regardless of how it occurs, it must be clear that there is strong executive commitment to the success of the AM initiative.

Experience has demonstrated the importance of this in both positive and negative contexts. In the development of the British Columbia Coast Forest Strategy, senior management initially provided clear direction that a new approach was needed, which was subsequently defined as AM by managers at the project management level. The executive direction was critical in spurring the company to action. Following a later change in ownership, however, when the new executives did not reiterate clear support for the initiative, support from other levels of the organization began to erode, due also to a lack of broad support within middle management.

Box 7: Risk aversion is alive and well. Itry to get people to understand that there is no such thing as a "no action alternative." There will be consequences, and they may be disastrous.

Adaptive management will be most successful within organizations that focus on learning. Where there appears to be a legislative mandate for AM, it should not be assumed that it alone is sufficient. There is a big difference between executive direction from within versus direction from some external requirement. In large measure, the critical need for clear executive direction is due to the fact that current institutions are not designed to carry out AM, and their corporate cultures may be averse to openly acknowledging uncertainty about how best to manage. In the long run, pursuing AM can mean embarking on a process of gradually shifting the corporate culture to more openly embrace uncertainty. Without strong executive support, this is likely to face deeply entrenched resistance.

\section{Problem Definition}

Because the problem definition used to frame an AM initiative will establish the focus for subsequent work, it is important to 
invest in getting it right. Failure to be clear about what the problem is will lead to later difficulties in maintaining an appropriate and effective focus.

Box 8: What we've learned is, pay now or pay later. Take the time to put the effort in up front, or you will need to do it later. If you don't do it, you are in trouble all the way through.

An important part of getting the right focus is paying attention to how it is expressed. In one case, despite engaging stakeholders early on in developing the problem definition and agreeing on a set of top problems, it became clear later that lack of success with the initiative was due in part to some "problems" being expressed as methods, rather than their clearly reflecting the underlying problem. For example, a problem statement might focus on identifying attributes of leave strips, when the underlying issue is how to prevent fish mortality. In another case, a forest management agency used an AM approach to validate the underlying assumptions about how they manage the forest. In retrospect, it would have been more helpful to frame the problem differently, giving decision makers more information on how the results could help them make other decisions.

Box 9: Looking back, often when things go south, it's because we weren't really focusing on the problem.

In fact, it may be better not to establish the focus as a problem at all, but instead to express it positively as a goal. In doing so, it is important to think about the larger context, by asking the question, "is this really the problem, or is it a manifestation of a larger problem?" If the problem definition does not capture the larger context but only reflects a piece of it, there is a danger that it will not be durable and the focus will be lost with a shift toward crisis management as other aspects of the real problem emerge over time. Figuring out what the durable questions are needs to be a responsibility of the organization and not left simply to research.

\section{Communication / Organizational Structure}

Effective, broad-based communication is necessary to gain the support needed within an organization for successful AM.

Box 10: If you think you are overcommunicating, keep doing it because you're probably not.
It is essential to keep in mind that the needed communication is two way; it's not just about communicating the need for the initiative to others. In order to develop a successful AM initiative, it is important to develop a sound mutual understanding of how the conduct and results of the initiative may impinge on the needs and interests of others. This can be a crucial aspect of working to define the problem or the focus of the AM initiative.

Box 11: It is absolutely critical to get people out in the woods: the whole dynamic changes.

Some of the challenges to effective communication have to do with the languages of different disciplines; disciplines also may have different world views. For example, biologists may be trying to figure out how to work within a system, whereas engineers may see value in restructuring it. Scientists tend to focus on what they don't know (they find such questions interesting!), whereas managers want to make decisions based on what they know now (and get impatient with scientists' complex discussions of uncertainty). Learning how to communicate effectively across disciplines can be like learning a foreign language. One of the challenges is finding venues for the kind of interaction that is needed.

Organizational structures can serve to either aid or inhibit broad-based communication. In many organizations, venues that support broad-based engagement are not well developed, and it may be necessary to seek out or create new opportunities for communication. For example, creating opportunities for executives, managers, and researchers to meet in a field setting has been found to be an effective mode of communication. It is also important to recognize that communication laterally is as important as communication vertically.

Given that, in the modern setting, it is not just about getting biologists to talk to foresters but also about the need to engage the social sciences, communication is becoming more challenging.

Box 12: One mechanism that has been successful is to create a team environment-get a mindset that we are together in this thing and each brings something valuable to the table.

It is important to take the need for communication seriously and not assume that people understand what you are trying to do. There is no "one right way" to have effective communication; what works in one situation might not work in another, and different approaches can be successful in different situations. 
There are two keys to good communications in an AM project. The first is to focus on learning the concerns of the people you are trying to communicate with. Maintain an active interestbe truly curious - about why others think the way they do, even if you do not agree with it. You open the doors to communication through true listening. Differences in values are not likely to change, but it's critical that they be understood. Different beliefs about management actions (and varying interpretations of existing evidence) can evolve into different treatments in an AM experiment, improving buy-in to the AM approach. The second key to good communication is to be sensitive to how people are responding to your process. Are you getting good contributions from all sides? Observe people: are they engaged? You may need to adapt to different people's styles, e.g., some people need to go out into the field to see it, and others can learn it in the boardroom.

\section{Community Involvement}

Box 13: If you want to close the loop, you are more likely to be successful if you have people involved who will be influenced by the activity.

The need for community involvement depends on the context in which AM will be implemented. In some cases, whether to involve the community at all is a choice. In other cases, the choice is how to do it. In certain contexts, such as small corporate initiatives on a plot or stand scale, community involvement may not be necessary. However, even in this context, involving people who could later be affected by the outcome can be important for enabling changes in policy or management actions. This is especially important if the outcome could have a large impact on them. Whenever there is a clear public investment in the issues to be addressed, community involvement is needed.

Early involvement, before decisions have been made, is important so that the community can contribute to the process of problem definition. This helps to build trust and later acceptance of the outcome. Local knowledge within the community can be a valuable resource in successful scoping and design of AM. Interested private landowners may provide valuable opportunities for conducting or participating in work on their property, or for providing a reference site.

Successful public engagement depends on being clear about what you are inviting the public to do.

Box 14: You need a facilitator to make sure it is done right. It can't be done ad hoc; without the necessary expertise, you will have a high probability of failure.
Everyone who is engaged has to be clear on this. People from the community will make valuable contributions about values and acceptable alternatives, but may not engage well in the technical details. It is important to go into it with your eyes open and with the right expertise.

In some situations, community involvement can be inhibiting, and it is important to make conscious choices about engaging the public. If a community does not want to be involved, it could mean that they do not understand the importance of the initiative, or perhaps that there is some hidden resistance. Unwillingness to engage does not necessarily reflect disinterest. It should be viewed with caution, as a possible signal that other avenues may be employed to stop the initiative. On the other hand, if it does reflect a lack of understanding, it is important to keep the door open to later engagement.

\section{Planning}

Adaptive management is carried out in the context of existing systems for forest management planning. Where the regulatory environment is highly risk averse, existing planning systems can act as an impediment to taking an AM approach. This is often rooted in the unstated assumption that acting on the basis of existing knowledge carries lower risk than conducting a management experiment to help to resolve uncertainty.

Box 15: Adaptive management really represents a fundamental, systemic reform about how we think about planning.

Risk aversion and various other factors have resulted in existing planning systems that tend to be rule based. This is antithetical to AM initiatives designed to explore the consequences of alternatives. Consequently, implementation of AM may require focused effort to explore how it can be done within the planning context. For example, the National Environmental Policy Act (NEPA) can be implemented in a mode that works either for or against AM. The Glen Canyon Dam (U.S. Department of the Interior, http://www.usbr.gov/ uc/rm/amp/, 2012) is an example of the former, where AM was explicitly proposed in the Environmental Impact Statement. The flip side is when planners or proponents identify a set of alternatives, pick one, and then select evidence to refute others. In many cases, there are probably good parts to each alternative, and perhaps what should be done is choose multiple alternatives to evaluate using an AM initiative. This rarely happens, although it can. The NEPA is a learning paradigm, so there is no reason an AM approach cannot be taken. Work may be needed, however, to sway people who are used to working within the planning paradigm in a mode that is counter to AM. 
Box 16: We need to acknowledge that people will have different values, and the best we can do is help them understand the trade-offs among those values.

Planning processes are increasingly about how to balance multiple values and objectives. At one time, planning was perceived as a scientific (technical) process, however, the view of planning has shifted as more values have had to be considered. Adaptive management practitioners need ways to help the public and the planners understand the consequences and trade-offs inherent in different choices. Adaptive management can explore ways to achieve multiple competing objectives in light of uncertainty, but does not address disagreements over competing values for which facilitation and mediation may be needed.

\section{Funding}

Box 17: The badnews: no budget this year. The goodnews: no budget this year. Why? Because we had to get creative; it can be very liberating.

Having adequate funding for AM is broadly recognized as important. In many respects, having or not having the necessary funds is an indicator of the presence, or lack, of executive support. It must be recognized, however, that even with strong executive support, external constraints can act to limit funding. It is important to keep in mind that the availability of funds cycles over time; funds may become available in the future even if they are currently limited.

\section{Staff Training}

Staff training is relevant to AM initiatives in three contexts: (1) the basic concepts of AM, (2) the details of the initiative, and (3) the knowledge gained to be incorporated in future policy or management action. The need for training in the second and third contexts will be fairly obvious, and most organizations will already have systems in place for providing such training. With a well-run AM initiative, the initiative itself can be an important mechanism for technical transfer.

Box 18: We asked "did you get any training?" Generally the answer was "no." So what level of commitment, and measure of importance, does that imply? Not much.

The need to provide training in the basic concepts of AM may be less obvious, but it can be critical to success. The absence of such training can convey a powerful message that the organization is not that serious about it. This sort of training is not just for staff at lower levels in an organization-to fill them in on what is going on. It is important for all levels of management. This is not new; other important initiatives such as fire management often involve training at all levels of an organization. Excellent resources are available for training forest managers and scientists in AM (British Columbia Ministry of Forests and Range website: http://www.for.gov. bc.ca/hfp/amhome/Publications/index.htm, 2013).

\section{How Adaptive Management Science is Conducted}

Box 19: We should not let science hang up the process; in thinking you can only do AM when you have teams of scientists.

It is naïve to think that large-scale AM can be as scientifically rigorous as small tightly controlled research experiments. There is a realistic trade-off that has to be recognized, and what is needed is a collaborative approach based on mutual understanding.

Box 20: We're trying to produce powerful evidence about things that are important.

On one hand, the rigor of the scientific method allows us to be clear about what we really know and what is in doubt. Without scientific rigor, initiatives billed as AM may be little more than undisciplined trial and error, a poor paradigm for effective learning.

On the other hand, trying to impose a high degree of scientific rigor can be seen as unnecessarily costly by managers and serve as an impediment to taking an AM approach.

Box 21: Rigor is important for overcoming lack of public trusthaving scientists validate what we are trying to do.

What is needed, especially in the early stages of experience with AM within an organization, is a reasonable balanceone that helps to assure true learning and enable management acceptance. In situations with a high degree of public involvement, a relatively high degree of rigor (early in the process) can be important in building the mutual trust needed to enable AM.

Box 22: You need a combination of active and passive AM. 
The AM literature recognizes two broad approaches: passive $\mathrm{AM}$ in which assessment of the expected best management alternative is undertaken and active AM in which plausible alternatives are compared by designing multiple management interventions as experiments. A key first step in deciding whether to follow a passive or active AM approach is being clear about what is already known.

Box 23: In a company situation, if you don't have passive AM you will stymie the potential for learning about AM.

It is important to engage scientists with management, at the stage of problem definition, to clearly identify what is known and what is needed. The rate at which new knowledge needs to be gained is also an important consideration.

Box 24: Good science is more important as the magnitude of the project grows. The level of rigor needed is linked to the stakes of the outcome.

The key is to engage people with the necessary expertise to help provide a clear answer. What might really be needed is the application of existing knowledge rather than an AM initiative. Or, what might be most appropriate is a combination of active AM at a smaller scale combined with passive AM on a larger scale. Deciding which way to go should not be the job of just researchers or just managers, but should be a collaborative effort.

\section{DISCUSSION}

McLain and Lee (1996) noted the AM literature paid little attention to the institutional issues surrounding AM and that the AM approach suffered from major flaws in its assumptions about the process of environmental decision making. Since that time, various authors have written about the institutional constraints to implementing AM. The results of our work update and reinforce the essential messages.

The importance of institutional constraints and of people in the AM process, a lack of understanding of the need for AM or of AM concepts, and reluctance to admit uncertainty and self-interest are broadly recognized in the literature as inhibiting factors. All these factors can lead to conflicts that frame people's commitment, or lack of it, to a proposed AM initiative (ESSA 1982, Lee 1993, 1999, Taylor et al. 1997, Walters 1997, Salafsky et al. 2001, Murray and Marmorek 2003, Stankey et al. 2003, 2005). Indeed, Lee (2003) frames the challenge as one of "integrating science and politics for the environment" where AM is the compass, and negotiation and conflict are the gyroscope. This marriage of science and politics was also noted by ESSA (1982) with the observation that implementation of AM is very much a political process. Walters (1997) and others lament the impediments that result from the self-interest of managers and researchers who see $\mathrm{AM}$ as a threat to existing research programs and management regimes.

Lee $(1993,1999)$ and Salafsky et al. (2001) both identify ethical issues as an important consideration in developing AM initiatives. The lives and welfare of people who use ecosystem resources, and who also see themselves as stewards of the resource, can be impacted by AM experimentation. Both withholding experimentation with management actions that could be more beneficial and implementing less effective practices as part of an experimental control raise concerns that can lead to conflict among stakeholders.

Enabling AM thus requires strong leadership in working with people to seek equitable resolution to conflicts and gain agreements that allow an AM initiative to move forward (ESSA 1982, Lee 1993, 1999, Walters 2007). Stankey et al. (2003) also emphasize the need for institutional capacity development to build understanding and commitment within an organization that is embarking on AM. Stankey et al. (2005) identify a requirement for a transition strategy from a command-control management approach to an AM approach as an important component of enabling AM.

The practice of AM can, however, be seen as being primarily a scientific endeavor. In this context, it may seem puzzling that the science aspects of AM are relegated to the third tier in our hierarchy. This is not meant to diminish the importance of scientific rigor in the design and implementation of AM. The scientific challenges of AM are substantial and clearly reflected in the writings of Walters (1986, 2003), Schwartz (1998), and numerous others. Walters (2007), however, observes that in more than 30 cases where there was consensus on the need for AM, it was never implemented. The most important factor leading to its failure was a lack of leadership. His observation, that how to convince decision makers to support management experiments remains a fundamental problem, echoes the message of McLain and Lee (1996) a decade earlier.

Although many of the people issues that can serve to inhibit AM may be addressed with strong leadership, transparent communication, and a sensitive approach to negotiation, some environmental values may prove intractable for AM. Stankey et al. (2003) and Walters (1997) report that conflicts over ecological values can stop attempts to pursue AM altogether. This is particularly likely when endangered species are involved, or legislation effectively prevents experimentation.

\section{CONCLUSIONS}

Doing high quality AM requires doing good science to learn from management experiments. Enabling AM is about 
working with people to appreciate their concerns, developing a common understanding, and producing an environment of trust that will allow AM to proceed. A key requirement is a clear and durable focus that is relevant to making management decisions. Key to defining a durable focus is asking, "why is this is a problem; what underlies it?". A properly specified focus can help to prevent an organization from slipping into crisis management mode, where it constantly shifts focus to newly emerging symptoms of a larger underlying problem.

Despite the challenges with AM, the results of the discussions with practitioners show that AM can be and is successful at a variety of scales for a variety of problems of differing complexity. Nineteen of 20 respondents in our survey indicated that some uncertainty was reduced, but more importantly, 14 indicated that a change in policy or management actions resulted. This is an important outcome, for even though uncertainty may be reduced, it does not guarantee that policy changes will occur.

Box 25: If you can pin down the decision maker on what the question is, they will be more likely to respond when you have learned something that helps them make the decision.

Closing the loop is not something that just comes at the end; it depends on effective communication and engagement at the beginning, when establishing the focus. If you are having difficulty getting new knowledge incorporated in policy and future management actions, it may mean that the initial focus was not what was really needed. Murry and Marmorek (2004) argue that closing the loop is the most commonly neglected part of environmental management.

Adaptive management is not simply about research at a management scale, the focus has to be relevant to management decisions, and the relevance needs to be understood clearly from the start. Understanding the unique context of each project, the corporate culture, stakeholder relationships, scale and focus of the project-AM leaders will need to tend the AM garden to prevent any one factor from becoming strongly inhibiting.

Responses to this article can be read online at: http://www.ecologyandsociety.org/issues/responses. $\mathrm{php} / 5686$

\section{Acknowledgments:}

We are grateful to the adaptive management practitioners who kindly participated in the survey and to the workshop participants, who discussed the survey results and their experiences: Bill Beese, Bernard Bormann, Bill Bourgeois, Jeff Brandt, Terry Johnson, Phil Kemp, Brian Nyberg, Hal Salwasser, Mike Schnee, Randy Selyma, and George Stankey. We also extend our sincere thanks to two anonymous reviewers whose thoughtful comments helped us to improve the paper.

\section{LITERATURE CITED}

Alverts, R., J. M. Calhoun, and R. L. Lee, technical editors. 2001. Organizational learning: adaptive management for salmon conservation conference proceedings. Olympic Natural Resources Centre, University of Washington, Forks, Washington, USA. [online] URL: http://www.adaptivemanagement. net/sites/default/files/Synthesis Report.pdf

Environmental and Social Systems Analysts Ltd. (ESSA). 1982. Review and evaluation of adaptive environmental assessment and management. Prepared for Environment Canada, Vancouver, British Columbia, Canada.

Lee, K. N. 1993. Compass and gyroscope integrating science and politics for the environment. Island Press, Washington, D. C., USA.

Lee, K. N. 1999. Appraising adaptive management. Conservation Ecology 3(2): 3. [online] URL: http://www. ecologyandsociety.org/vol3/iss $2 /$ art $3 /$

Marmorek, D. R., L. Greig, C. Murray, and D. C. E. Robinson. 2006. Enabling adaptive forest management-final report. Prepared for the National Commission on Science for Sustainable Forestry by ESSA Technologies Ltd., Vancouver, British Columbia, Canada. [online] URL: http://ncseonline. org/sites/default/files/D1\%20Final\%20Report\%20NCSSF\% 20Project $\% 20 \mathrm{D} 1$ Adaptive $\% 20$ Forest $\% 20 \mathrm{Mgmt} \% 20 \mathrm{Final} \%$ 2018\%20May\%2006.pdf

MacDonald, G. B., R. Arnup, and R. K. Jones. 1997. Adaptive forest management in Ontario: a literature review and strategic analysis. Forest Research Information Paper No. 139, Ontario Ministry of Natural Resources, Peterborough, Ontario, Canada.

McDonald, G. B., J. Fraser and P. Gray, editors. 1999. Adaptive management forum: linking management and science to achieve ecological sustainability. Proceedings of the 1998 Provincial Science Forum, Ontario Ministry of Natural Resources, Peterborough, Ontario, Canada.

McLain, R. J., and R. G. Lee. 1996. Adaptive management: promises and pitfalls. Environmental Management 20(4):437448 .

Mitchell, R. J., L. A. Schulte, M. L. Hunter, Jr., J. F. Franklin, R. K. McIntyre, and B. J. Palik. 2004. Conservation theory and forest management: foundation, utility and research 
needs. Final Report for the National Commission on Science for Sustainable Forestry, Project B2, National Council for Science and the Environment, Washington, D.C., USA. [online] URL: http://ncseonline.org/sites/default/files/B2\% 20Final\%20Report.pdf

Murray, C., and D. Marmorek. 2003. Adaptive management and ecological restoration. Pages 417-428, in P. Freiderici, editor. Ecological restoration of southwestern ponderosa pine forests. Island Press, Washington, D.C. and Covelo, California, USA; London, UK.

Murray, C., and D. Marmorek. 2004. Adaptive management: a spoonful of rigour helps the uncertainty go down. Sixteenth International Annual Meeting of the Society for Ecological Restoration, 23-27 August 2004, Victoria, British Columbia, Canada.

Salafsky, N., R. Margoluis, and K. Redford. 2001. Adaptive management: a tool for conservation practitioners. World Wildlife Fund, Washington D.C., USA.

Schwartz, C. J. 1998. Studies of uncontrolled events. Pages 19-39 in V. Sit and B. Taylor, editors. 1998. Statistical methods for adaptive management studies. British Columbia Ministry of Forests, Victoria, British Columbia, Canada.

Stankey, G. H., B. T. Bormann, C. Ryan, B. Shindler, V. Sturtevant, R. N. Clark, and C. Philpot. 2003. Adaptive management and the Northwest Forest Plan: rhetoric and reality. Journal of Forestry 101(1):40-46.

Stankey, G. H., R. N. Clark, and B. T. Bormann. 2005. Adaptive management of natural resources: theory, concepts, and management institutions. General Technical Report PNW-GTR-654. U.S. Department of Agriculture, Forest Service, Pacific Northwest Research Station. Portland, Oregon, USA.

Taylor, B., L. Kremsater, and R. Ellis. 1997. Adaptive management of forests in British Columbia. British Columbia Ministry of Forests, Victoria, British Columbia, Canada.

Walters, C. 1986. Adaptive management of renewable resources. MacMillan Publishing Company, New York, New York, USA.

Walters, C. 1997. Challenges in adaptive management of riparian and coastal ecosystems. Conservation Ecology 1(2):1. [online] URL: http://www.ecologyandsociety.org/vol1/iss $2 /$ $\underline{\operatorname{art} 1 /}$

Walters, C. 2003. Folly and fantasy in the analysis of spatial catch rate data. Canadian Journal of Fisheries and Aquatic Sciences 60:1433-1436. http://dx.doi.org/10.1139/f03-152

Walters, C. 2007. Is adaptive management helping to solve fisheries problems? Ambio 35(4):304-307. 